\title{
Fundamentos para a Educação e para a Educação Ambiental na perspectiva da Teoria Crítica
}

\author{
Leda Belitardo de Oliveira Pereira ${ }^{1}$ \\ Fernanda Sueko Ogawa ${ }^{2}$ \\ Elisângela Soares Siqueira dos Santo ${ }^{3}$ \\ Raquel Gonçalves Octávio ${ }^{4}$
}

\section{Resumo}

Este artigo tem como ponto de partida o ato educativo numa concepção abrangente, considerando-o como processo de aprofundamento teórico que se materializa em práticas até mesmo fora de um contexto institucionalizado, para a Educação e para a Educação Ambiental. A fundamentação deste texto é da Teoria Crítica, na perspectiva de Theodor Ludwig Wiesengrund-Adorno (1903-1969), Herbert Marcuse (18981979) e Jürgen Habermas (1929-) como possibilidade de uma educação geradora de reflexão a caminho da emancipação dos indivíduos e da sociedade.

Palavras-chave: Fundamentos da educação. Educação ambiental. Teoria crítica.

\begin{abstract}
This paper has as its starting point the educational act in a comprehensive conception, considering it as a process of theoretical deepening that materializes in practices even outside an institutionalized context, for Education and for Environmental Education. The basis of this text is from Critical Theory, from the perspective of Theodor Ludwig Wiesengrund-Adorno (1903-1969), Herbert Marcuse (1898-1979) and Jürgen Habermas (1929-) as the possibility of an education that generates reflection on the way to the emancipation of individuals and society.
\end{abstract}

Keywords: Fundamentals of education. Environmental education. Critical theory.

\footnotetext{
${ }^{1}$ Doutoranda em Educação pela Unesp de Rio Claro - linha: Educação Ambiental; Diretora de Escola Técnica no Centro Estadual de Educação Tecnológica Paula Souza. E-mail: leda.belitardo@gmail.com

${ }^{2}$ Mestranda em Educação pela Unesp de Rio Claro - linha: Educação Ambiental. Bióloga pela mesma Instituição.E-mail: feerogawa@gmail.com

${ }^{3}$ Mestranda em Educação pela Unesp de Rio Claro - linha: Educação Ambiental. Licenciada em Letras e professora da Secretaria Municipal de

Ensino de Rio Claro. E-mail: elisiqueira2008@gmail.com

${ }^{4}$ Doutora em Educação pela Unicamp e professora da Pós-graduação em Educação do Centro Universitário de Jaguariúna Unifaj. E-mail: e215dir@cps.sp.gov.br
} 


\section{Introdução}

O pensamento central da Teoria Crítica nasce em um grupo de intelectuais alemães considerados "marxistas não ortodoxos" nos anos 20 do século XX, os quais fundam o Instituto de Pesquisa Social de Frankfurt na Alemanha, comumente chamado de "Escola de Frankfurt", como um espaço de investigação filosófica, sociológica e cultural (PUCCI, 1994).

A Teoria Crítica é amplamente divulgada a partir do ensaio de um dos pensadores expoentes da Escola de Frankfurt: Max Horkheimer (1895-1973), por intermédio do seu ensaio "Teoria Tradicional e Teoria Crítica" em 1937. Nesta obra, o autor descreve a Teoria Crítica - de fundamento marxista, contudo, sob uma nova perspectiva, oposta à Teoria Tradicional (cartesiana/positivista) e crítica à economia política da época. Para Horkheimer, a Teoria Tradicional nasce do pensamento filosófico moderno de Renè Descartes (1596-1650), que considerava separadamente sujeito e objeto em um cientificismo altamente especializado e de natureza abstrata, nas quais as ideias devem ter objetivo prático e lógico para ter valor, como aponta Arantes (1989, p. 12):

\footnotetext{
Descartes - diz Horkheimer - fundamentou o ideal de ciência como sistema dedutivo, no qual todas as preposições referentes a determinado campo deveriam ser ligadas de tal modo que a maior parte delas pudesse ser derivada de algumas poucas. [...] a teoria tradicional encontrou amplas justificativas para um tal tipo de ciência no fato de que os sistemas assim construídos são extremamente aptos à utilização operativa, isto é, sua aplicabilidade prática é muito vasta.
}

A Teoria Crítica, ao contrário, considera como objeto os homens, produtores de suas histórias e coloca o social no cerne dos problemas da humanidade, pois as situações não são tão somente dadas pela natureza, mas são dadas também pelo poder do homem sobre ele mesmo (ARANTES, 1989).

Os indivíduos se encontram atrasados em suas relações humanas e em suas relações com a natureza, legitimando uma agressividade primitiva que impulsiona a destruição e fornece perigo ao ambiente social e natural. Neste contexto, o processo educativo precisa ser reordenado em seus objetivos para priorizar o impedimento desta agressividade, a barbárie e a falência da cultura. O comportamento crítico deve fazer parte da construção histórica da sociedade, na luta contra dicotomias como: "pensamento-ação", "indivíduo-sociedade", "homem-natureza", buscando sua transformação pela luta vinculada à reorganização de um mundo esclarecido (ADORNO, 2003).

\section{Da obra "Educação e Emancipação": base para algumas reflexões pedagógicas}

Em 1995, o professor Wolfgang Leo Maar, da Universidade Federal de São Carlos traduziu um conjunto de entrevistas e conferências de Theodor Adorno, entre elas o debate dele com o educador Hellmut Becker, na Rádio de Hessen transmitido em 13 de agosto de 1969, o qual se encontra no livro "Educação e Emancipação" (PUCCI, 1994).

Neste debate, Adorno (2003) aponta para duas perspectivas concretas para refletirmos sobre a relação teoria e prática educacional: 
a. Acerca da necessidade de conceber a Educação por processos auto-reflexivos, começando pela infância, a qual seja capaz de desarmar o extremismo, a barbárie, a insensibilização e a exploração humana, para o desenvolvimento da crítica ao pensamento instrumentalizado das coisas e dos homens. Em outras palavras, Adorno (2003, p. 125-126), acredita que a desbarbarização deva ser um dos principais objetivos da Educação.

b. b- Para o desenvolvimento da autonomia e emancipação do sujeito e da capacidade de resistência e enfrentamento dos momentos de opressão. O autor salienta o sentido de construir uma racionalidade ou consciência que seja apreendida como o "pensar” em relação à realidade, não apenas pela construção lógica formal do pensamento cartesiano, sobretudo, para o desenvolvimento da capacidade de elaborar/criar experiências intelectuais livres, ou seja, "a educação para a experiência é idêntica à educação para a emancipação" (ADORNO, 2003, p.150-151).

Estas perspectivas são delineadas por Adorno (2003) para que a sociedade não corra o risco de se esquecer da história, pois quando a humanidade se aliena da memória, ela legitima a objetividade do poder hegemônico, reforçando a ideologia dominante. $\mathrm{O}$ autor remete-se à história de terror que a Alemanha nazista sofreu pelas condições objetivas existentes na época, as quais legitimaram as forças ideológicas e o estado de alienação da sociedade.

Neste contexto, o autor enfatiza que a missão da Educação é tornar o indivíduo consciente do processo de “modelagem” e instauração ideológica em que está inserido, para rupturas intelectuais conceituais, capazes de provocar comportamentos e atitudes de resistência ao modelo posto. O indivíduo se torna emancipado quando reconhece as figuras de autoridade e o conjunto de manipulações de poder, superando sua condição de minoridade. Este reconhecimento permite a legitimação da sua própria identidade e o leva a emancipação:

A seguir, e assumindo o risco, gostaria de apresentar a minha concepção inicial de educação. Evidentemente não a assim chamada modelagem de pessoas, porque não temos o direito de modelar pessoas a partir do seu exterior; mas também não a mera transmissão de conhecimentos, cuja característica de coisa morta já foi mais do que destacada, mas a produção de uma consciência verdadeira. Isto seria inclusive da maior importância política; sua ideia, se é permitido dizer assim, é uma exigência política. Isto é: uma democracia com o dever de não apenas funcionar, mas operar conforme seu conceito, demanda pessoas emancipadas. Uma democracia efetiva só pode ser imaginada enquanto uma sociedade de quem é emancipado (ADORNO, 2003. p. 141).

Contudo, o autor esclarece que esta superação é extremamente difícil porque os indivíduos interiorizam as personalidades dominadoras tradicionalmente, desde o seu genitor opressor, passando por um processo de fraqueza do eu, não conseguindo se libertar do poder dominante. Para ele, o único modo de concretizar a emancipação é por intermédio de pessoas que orientem outras para uma educação esclarecida e criticamente consciente das contradições sociais e da necessidade de ruptura dos mecanismos de identificação com a menoridade, a caminho da superação de nossas impotências para a transformação daquilo que pensamos e daquilo que fazemos (ADORNO, 2003, p.178-185). 
Para Adorno (2003) vivemos em uma sociedade heterônoma na qual nenhum indivíduo pode agir e existir de acordo com suas próprias determinações políticas, sobretudo, no âmbito institucional da escola. Há sólidas barreiras para a educação a caminho da liberdade e da emancipação dos sujeitos políticos, até mesmo um conformismo e uma consciência ingênua, falseada pelo discurso hegemônico que impede o esclarecimento.

O autor enfatiza que:

s pessoas que nestes termos procuram demonstrar com franqueza a sua própria ingenuidade e imaturidade política sentem-se, por um lado, como sendo sujeitos políticos, aos quais caberia determinar seu próprio destino bem como organizar a sociedade. Mas deparam-se, por outro lado, com as sólidas barreiras impostas pelas condições vigentes. Como não podem romper essas barreiras mediante o pensamento, acabam atribuindo a si mesmos, ou aos adultos, ou aos outros, esta impossibilidade real que lhes é imposta. Eles mesmos terminam por se dividir mais uma vez em sujeito e objeto. De qualquer modo, a ideologia dominante hoje em dia define que, quanto mais as pessoas estiverem submetidas a contextos objetivos em relação aos quais são impotentes, ou acreditam ser impotentes, tanto mais elas tornarão subjetiva esta impotência (ADORNO, 2003. p. 35).

É necessário, portanto, converter essa impotência de transformação por intermédio da construção da crítica imanente na sociedade, na qual a Educação deva ser portadora de instrumento de resistência e luta para consciência e esclarecimento do sujeito político.

A Educação, como prática política e social, tem por finalidade construir sujeitos críticos e participativos despidos do discurso ideológico hegemônico, na construção de comportamentos colaborativos, envolvidos com a democracia e atuantes em sua esfera histórica.

[...] a própria organização do mundo em que vivemos e a ideologia dominante — hoje muito pouco parecida com uma determinada visão de mundo ou teoria —, ou seja, a organização do mundo converteu-se a si mesma imediatamente em sua própria ideologia. Ela exerce uma pressão tão imensa sobre as pessoas, que supera toda a educação (ADORNO, 2003. p. 143).

Para Adorno (2003), a ideia de emancipação é abstrata no ato educativo, posto que o mundo está organizado sob forte pressão ideológica dominante a ponto de cegar os sujeitos e não permitir o esclarecimento. Para o pensador, a emancipação se concretiza por intermédio de uma ação dialética (debates, discussões, argumentações, contra-argumentações) num processo de adaptação, de luta e de resistência, que promova o esclarecimento das condições políticas, econômicas e sociais da sociedade contemporânea, no intuito de superar as lacunas que impedem a instauração de princípios fundamentais para viver a e na democracia.

Sob o ponto de vista da Educação Ambiental, a crítica abordada por Adorno nos remete a uma reflexão profunda acerca da impotência desta ação emancipatória, para nos movimentarmos, de maneira esclarecida, contra a 
lógica instrumental, cientes das contradições que ela carrega historicamente, a qual escraviza e barbariza a relação do ser humano com a sociedade e a relação do ser humano com a natureza.

\section{As contribuições do pensamento habermasiano para a Educação}

Conforme descreve Freitag (1994, p. 27-30), Jürgen Habermas (1929-) fez renascer uma nova Teoria Crítica, desenvolvendo linhas próprias de trabalho na superação das ideias primárias de seus mestres. Prosseguindo de modo original e inovador, retomou o debate da obra de Horkheimer, Benjamin, Marcuse e Adorno, a fim de criticar, discutir e transcender o pensamento crítico frankfurtiano. A partir da década de 70 do século XX, houve um movimento editorial intenso do autor e suas reflexões resultaram em problemáticas acerca da legitimação do Estado moderno e da elaboração de uma Teoria do Agir Comunicativo entre os anos de 1981-1984 em dois volumes.

Habermas (2012, p. 652-665) aponta que a crítica da razão instrumental concebida por Adorno e Horkheimer, evidenciava as relações entre sujeitos e objetos, desconsiderando as relações interpessoais entre sujeitos e sujeitos, determinante para o modelo das trocas no contexto reprodutivo do sistema capitalista. Ele demonstra no último capítulo do primeiro volume do seu ensaio Teoria do Agir Comunicativo que:

[...] uma mudança de paradigma em direção à teoria da comunicação permite o retorno a um empreendimento que, a seu tempo, viu-se interrompido pela crítica da razão instrumental; essa mudança de paradigma pode consentir na retomada de tarefas de uma teoria social crítica que ficaram abandonadas. (p. 665, grifos do autor).

De acordo com Mühl (1998, p. 244-245), Habermas herda a Teoria Crítica como intelectual da "segunda geração", no entanto, na crítica à razão instrumental, preocupa-se em superar os pensadores da primeira geração (seus mestres: Horkheimer e Adorno), atacando suas análises radicais da racionalidade, por acreditar serem insuficientes e inacabadas. Ele inaugura, então, um pensamento que reconstrói a Teoria Crítica da dimensão instrumental-técnica predominante das relações sociais contemporâneas, enfatizando que esta racionalidade vai além da mera perspectiva instrumental. Por estar imbricada nas interações sociais, necessariamente, é constituída pela dimensão comunicativa, concebida em sua Teoria do Agir Comunicativo. Segundo o autor:

[...] a teoria da argumentação ganha significado especial, porque é dela a tarefa de reconstruir os pressupostos e condições formal-pragmáticos de um comportamento explicitamente racional (HABERMAS, 2012, p. 21).

A ideia central da Teoria do Agir Comunicativo é conduzir a crítica à razão não apenas das ações dos sujeitos, mas na racionalização das ações da sociedade, as quais são providas de competência comunicativa que tornam possível a relação entre razão comunicativa e condições de reprodução da sociedade humana.

Para Habermas (2012), a vida de uma sociedade se constitui em um processo de produção mediado pelos atos de fala, os quais são legitimados por três pretensões discursivas na atividade social: pretensão da verdade, pretensão à normatização e pretensão à autenticidade do sujeito. Tais pretensões são concretizadas na razão de sujeitos 
capazes de agir e falar, exteriorizando uma verdade ou um êxito ou de seguir uma norma vigente, legitimando um comportamento racional, e ainda, no saber corporificado em ações de vivências subjetivas presentes no mundo social ou no mundo subjetivo de cada um, incluindo o processo educativo.

As contribuições de Habermas para a Educação tem como ponto de partida a crítica ao individualismo e à dominação, constituídas na história da sociedade ocidental, por intermédio do desenvolvimento da razão instrumental, a qual é apropriada na ação comunicativa e no processo educacional.

Em seu pensamento, tenta formular um conceito de racionalidade que supere o reducionismo desta razão instrumental e busca desenvolver uma teoria social que articule o mundo da vida e do sistema (PRESTES, 1998, p. 222).

No pensamento habermasiano, a autora enfatiza que:

É o mundo da vida (Lebenswelt) que permite aos indivíduos adotar orientações para as ações consideradas racionais. Inicialmente, essa racionalidade do mundo da vida se ancora nos sistemas culturais de interpretação ou nas imagens místicas do mundo, refletindo um saber que garante a coerência da diversidade de orientações da ação. Habermas se defronta então com a pluralidade histórica e cultural das visões do mundo (PRESTES, 1998, p.224).

Segundo a autora, essa racionalidade pretendida por Habermas, depende da capacidade humana em estabelecer relações com o mundo físico (mundo da vida) nas relações com os objetos e com outros em meio a desejos e a sentimentos que orientam as ações e as práticas comunicativas, em meio às pluralidades de visões de mundo. Na perspectiva habermasiana, a racionalização das imagens de mundo é sustentada por processos educativos que as sociedades dispõem e transmitem por intermédio das instituições.

Do pensamento habermasiano, Repa (2008, p.166-167) evidencia que a ação instrumental (derivada da razão instrumental), busca eficiência em ações racionais de sujeitos que influenciam outros sujeitos ou utilizam/fabricam coisas/produtos como meio para se obter outra coisa/produto (lógica capitalista). A racionalidade desse tipo de ação é caracterizada como um sistema e, sua reprodução, sustenta as estruturas das esferas econômicas, políticas e culturais sobre o mundo da vida. Este mundo da vida se perpetua por intermédio das interações comunicativas e pela ação comunicativa, que buscam reconhecimento e pretensões de validade do que é dito para o prosseguimento da interação e de um consenso livremente produzido a caminho da ação emancipatória.

Na perspectiva da Educação Ambiental, o pensamento habermasiano contribui para entendermos que os atos de fala de professores e de alunos necessitam evitar a abstração e dar significação ao dito e ao que é construído por meio das relações interpessoais. Segundo Habermas (2012), os atos de fala devem buscar a verdade das proposições, a justiça das normas e a sinceridade/ veracidade de sujeitos autênticos. Dito de outro modo, o mundo vivido no contexto natural e social deve ser constituído de fatos e de hábitos originais, validados e compartilhados socialmente para a sua descolonização e dominação, a caminho de processos de aprendizagem que resultem em transformações e a verdadeira libertação do sistema (razão instrumental capitalista).

\section{A validade do pensamento de Herbert Marcuse para o contexto Educacional}

Como expoente da Escola de Frankfurt, Herbert Marcuse (1898-1979) apresenta uma obra vasta e abundante. Suas produções estão direcionadas a uma crítica à Racionalidade Instrumental. Para ele a máquina dominaria o homem e não o contrário, as pessoas seriam massificadas. 
De acordo com Terra (2008, p.137), é apropriado apontar três perspectivas do Marcuse que permite diferenciá-lo do Horkheimer e Adorno. Uma dessas linhas é a sua ligação de aproximação com a Filosofia contemporânea, enquanto os outros dois pensadores apontados apresentavam um afastamento; Outra particularidade é sua perspectiva militante, "Marcuse prefere correr o risco de ser mal entendido a simplesmente não ser entendido". E a terceira visão é que para Marcuse, o pano de fundo para suas concepções são os sujeitos históricos do pós-guerra nos movimentos político-sociais enquanto para Horkheimer e Adorno suas análises de investigação discorrem com o Nazismo, o Stalinismo e a Indústria Cultural.

Nos artigos escritos em meados de 1930 até o livro "Razão e Evolução" de 1941, Marcuse parte para a tentativa de superar os limites da racionalidade subjetiva. Neste contexto, a Razão conteria a ideia de liberdade, na qual o sujeito poderia fazer suas escolhas e assumindo todos os riscos sobre, por exemplo, o certo e errado. Almejando "produzir um pensamento universal, que compreenderia racionalmente o mundo e a si mesmo". Porém, nesta sociedade, a "liberdade seria apenas uma falsa consciência de liberdade", uma vez que contribuiria para a manutenção da ordem de dominação, por meio da justificativa da racionalidade e moral instituídas na modernidade, assim como coloca a autora

Ao ser internalizada por um sujeito empírico (individual), juntamente com os conceitos de liberdade e de individualidade, tal categoria constituir-se-ia em um fundamento ou em uma justificativa da racionalidade e da moral instituídas na modernidade, conformando a consciência do indivíduo aos valores transmitidos pela tradição e restringindo a ação desenvolvida por ele à manutenção de uma ordem social baseada na miséria e na dominação da maioria (PAGNI, 2003, p.82).

Passando por "Eros e Civilização" de 1940, onde realiza uma crítica mais determinada, em busca da superação da racionalidade subjetiva, através de outro conceito de subjetividade, que poderia ser pensado a partir de uma educação estética que levasse em conta elementos sensíveis e instintuais, caminhando na contra-corrente dos mecanismos de dominação da sociedade industrial. Para isso, reflete acerca de uma "alternativa teórica para práxis revolucionária e intenta sobre um projeto de transformação radical da estrutura social vigente". Vale ressaltar que para Marcuse, o sujeito da práxis histórico seriam todos aqueles que sentissem a opressão, que fossem reprimidos pela civilização atual, ou seja, não somente o proletariado, mas os diversos segmentos sociais, como os negros, estudantes entre outros (PAGNI, 2003). Freud faz parte dos estudos de Marcuse, pois este último acredita que sem conhecermos a funcionalidade da subjetividade humana a luta política seria ineficaz (LOUREIRO, 2005).

Em uma de suas obras de referência “A Ideologia da Sociedade Industrial - O homem Unidimensional” do ano de 1966, Marcuse passa a ter um pensamento negativo em relação às possibilidades de transformação radical da sociedade por meio da práxis e constituição de uma nova subjetividade. Mesmo neste momento, não afasta-se de seu engajamento político (PAGNI, 2003).

Marcuse procura expor como o conceito de Razão é aplicado pela Sociedade Industrial que engloba o Irracional e ainda apresenta críticas a essa sociedade industrial e ao capitalismo, ao qual o processo de emancipação do homem não é considerado, nesse sentido, a autonomia da razão. 
Aponta que, a racionalidade tecnológica expandida pelo capitalismo é uma racionalidade que se julga superior à natureza e com domínio do próprio homem e não atende aos objetivos de proporcionar o aumento da qualidade de vida além de impossibilitar a libertação dos indivíduos, ou seja, são formas de domínio indiretas da sociedade, da escola e do trabalham e regulam o pensamento do homem, tornando-o Unidimensional.

\begin{abstract}
Os produtos doutrinam e manipulam; promovem uma falsa consciência que é imune a sua falsidade. E, ao ficarem esses produtos benéficos à disposição de maior número de indivíduos e de classes sociais, a doutrinação que eles portam de ser publicidade tornam-se um estilo de vida - muito melhor do que antes - e, como um bom estilo de vida, milita contra a transformação qualitativa. Surge assim um padrão de pensamento e comportamento unidimensionais no qual as ideias, as aspirações e os objetivos que por seu conteúdo transcendem o universo estabelecido da palavra e da ação são repelidos ou reproduzidos a termos desse universo (MARCUSE, 1978, p.32).
\end{abstract}

Seu pensamento em relação à sociedade industrial e ao exagero produtivo e serviços impõe um sistema social repressivo e que induz o indivíduo a alienação, transformando a Razão em submissão.

O conceito de alienação parece torna-se questionável quando os indivíduos se identificam com a existência que lhe é imposta e têm nela seu próprio desenvolvimento e satisfação. Essa identificação não é uma ilusão, mas uma realidade. Contudo, a realidade constitui uma etapa mais progressiva da alienação. (MARCUSE, 1978, p. 31).

Suas obras não se aprofundam nos problemas especificamente da escola, mas apresenta a questão da emancipação, como princípio das modificações e impulso para transformação, ou seja, resgatar a racionalidade crítica do ser humano, despertando para a manipulação e para as falsas necessidades impostas pela ideologia da sociedade industrial, podendo ser essas limitações superadas através do conhecimento, ou seja, uma educação como emancipatória.

E para que aconteça essa emancipação de acordo com Marcuse expressa Terra (2008, p. 146), seria necessário uma mudança social da "tecnologia que foi herdada", uma tomada de consciência da classe para contestação da ordem imposta pelo "progresso".

O progresso da racionalidade tecnológica está liquidando os elementos de oposição e transcendentes da "cultura superior". Eles sucumbem, de fato, ao processo de dessublimação que predomina nas regiões avançadas da sociedade contemporânea" (MARCUSE, 1978, p. 69)

E a educação nesse contexto se apresenta pelas reflexões de Marcuse (1978, p. 69), como uma concepção de cultura que disputa para a libertação do corpo e da mente dos homens que estão subordinados às organizações impostas pelo mercado industrial. Vale ressaltar, que ele aponta que neste momento "não é a deterioração da cultura superior, numa cultura de massa, mas a refutação dessa cultura pela realidade" pela sociedade industrial. 
A ideia de uma transformação qualitativa se apresenta na obra de Marcuse, pelo viés dos movimentos das classes sociais que são capazes de investir nessas transformações como nos assegura Terra (2008), uma alteração da racionalidade científica.

No que se refere à Educação Ambiental, apresentando como base os preceitos à racionalidade tecnológica da sociedade capitalista, Marcuse (1978, p.36) enfatiza a dinâmica da dominação do homem e da natureza e exploração dos seus recursos, isto é, o desenvolvimento das forças produtivas encaminha o homem à apropriação privada da Natureza e a sua redução à posição de matéria-prima. Apesar de longa, a citação abaixo corresponde bem essa exploração:

A conquista da natureza se reduz a cegueira, a ferocidade e a fertilidade da Natureza - o que implica reduzir a ferocidade do homem contra a natureza. $\mathrm{O}$ cultivo do solo é qualitativamente diferente da destruição do solo; a extração dos recursos naturais, da exploração perdulária; a limpeza das florestas, do desflorestamento em massa. Pobreza, doença e crescimento canceroso são tão naturais quantos os males humanos - sua redução e remoção é libertação de vida. A civilização alcançou essa "outra" transformação libertadora em seus jardins, parques áreas protegidas, tratou a natureza como tem tratado o homem - como um instrumento de produtividade destrutiva (MARCUSE, 1978, p. 221).

Para Isabel Loureiro (2005), o autor apresenta uma preocupação ecológica, pensando a respeito do desenvolvimento econômico, característico do sistema hegemônico, pelo simples desenvolvimento, que resultaria em uma relação destrutiva em relação a natureza. Uma mudança dos paradigmas desenvolvimentistas poderia fazer com que a natureza deixasse de ser objeto de dominação dos homens.

Marcuse apresenta o Paradigma da Revolução a seu limite, conforme apresenta Terra (2008, p. 157)

Já que procura pensar os movimentos sociais, culturais e artísticos de seu tempo, mas acaba com isso por deixar clara, contra sua vontade, a insuficiência desse mesmo paradigma, visto que não consegue apreender alguns aspectos fundamentais daqueles movimentos.

Marcuse nesse sentido, investe suas perspectivas em uma nova esquerda, formada agora por estudantes e por grupos à margem da sociedade e apresenta um distanciamento da política partidária acreditando apenas em uma política Revolucionária. O que o torna, como um dos principais influenciadores para os movimentos Estudantis de 1968

Pagni (2003) aponta que Marcuse sempre teve uma sensibilidade ímpar para tratar de temas resultantes das lutas dos movimentos sociais emergentes e comunicar seu pensamento crítico aos movimentos dos estudantes, militantes feministas, ativistas dos direitos humanos e do ambiente. $\mathrm{O}$ autor buscava "nutrir teoricamente a prática política desenvolvida pelos movimentos sociais emergentes". Herbert Marcuse teve notória influência nos movimentos que desembocaram, a partir de 1960, no ambientalismo. Movimentos estes marca- 
dos pela contracultura, partindo contra o padrão de vida pautado no individualismo, homogeneização cultural e consumo (LOUREIRO, 2004).

\section{Considerações Finais}

Podemos constatar que as contribuições habermasiana para a Educação tem como ponto de partida a crítica ao individualismo e à dominação, constituídas na história da sociedade ocidental, por intermédio do desenvolvimento da razão instrumental, a qual é apropriada na ação comunicativa e no processo educacional. Seu pensamento foi marcado por um conceito de racionalidade para superar o reducionismo da razão instrumental, buscando desenvolver uma teoria social de integração do mundo da vida e do mundo do sistema.

Já na concepção marcusiana, há uma evidente preocupação ecológica com reflexões relacionadas ao modelo de desenvolvimento econômico, característico do sistema hegemônico, pelo simples desenvolvimento, que resultaria em uma relação destrutiva em relação a natureza. Uma mudança dos paradigmas desenvolvimentistas poderia fazer com que a natureza deixasse de ser objeto de dominação dos homens. No âmbito da Educação Ambiental, apresentando como base os preceitos à racionalidade tecnológica da sociedade capitalista, Marcuse (1978, p.36) enfatiza a dinâmica da dominação do homem e da natureza e exploração dos seus recursos, em outras palavras, o desenvolvimento das forças produtivas leva o homem à apropriação privada da Natureza.

Neste contexto, entendemos que a Teoria Crítica desde sua concepção nos anos 20 do século XX contribui para profundas reflexões do contexto Educacional, mesmo que indiretamente, nas obras de seus autores mais expoentes. A riqueza da sua constituição teorética permite caminhos para se pensar com rigor crítico as atividades da sociedade contemporânea de modo autêntico e peculiar, sobretudo nos fundamentos educacionais atuais.

\section{Referências}

ADORNO, Theodor Ludwig Wiesengrund. Educação e emancipação. Tradução Wolfgang Leo Maar. 2 ed. Rio de Janeiro/São Paulo: Editora Paz e Terra S.A. 2003.

ARANTES, Paulo. Eduardo. Horkheimer e Adorno. Vida e Obra. 3 ed. São Paulo: Nova Cultural, 1989. (Os Pensadores).

BARONI. Vivian. Para Além do Unidimensional: Marcuse e a educação estética. Linhas Críticas: Revista da Faculdade de Educação - UnB, n. 46, v. 21.Set. 2015. Trimestral. ISSN 198110431.

Subjetividade, Cultura e Educação em Herbert Marcuse. Revista Subjetividades: Universidade de Fortaleza Unifor, v.16, n.4, jan.2016. Quadrimestral. INSS 23590777.

FREITAG, Bárbara. A Teoria Crítica: ontem e hoje. São Paulo: Brasiliense, 2004.

HABERMAS, Jürgen. Teoria do Agir Comunicativo 1: Racionalidade da ação e racionalização social. Tradução: Paulo Astor Soethe. São Paulo: WMF Martins Fontes, 2012. 
. Teoria do Agir Comunicativo 2: Sobre a crítica da razão funcionalista. Tradução: Flávio Beno

Siebeneichler. São Paulo: WMF Martins Fontes, 2012.

HERMANN, Nadja. Validade em Educação: Intuições e problemas na recepção de Habermas. Porto Alegre: EDIPUCRS, 1999.

LOUREIRO, C. F. B. Educação Ambiental Transformadora. In: Layrargues, P. P. (org.). Identidades da Educação Ambiental Brasileira. Brasília: MMA/DEA, 2004.

LOUREIRO, I. Herbert Marcuse - Anticapitalismo e Emancipação. Trans/Form/Ação, São Paulo, 28(2): 7-20, 2005.

MAAR, Wolfgang Leo. A formação em questão: Lukács, Marcuse e Adorno. A gênese da indústria cultural. In: ZUIN, Antônio Álvaro Soares; PUCCI, Bruno; RAMOS-DE-OLIVEIRA, Newton (orgs). A Educação Danificada: contribuições à teoria crítica da Educação. 2 ed. Petrópolis, RJ: Vozes; São Carlos, SP: EdUFSCAR, 1998. p. $45-88$.

MARCUSE, Herbert. A Ideologia da Sociedade Industrial: O Homem Unidimensional. 6. ed. Rio de Janeiro: Zahar Editores S. A. 1978.

MÜHL, Eldon Henrique. Modernidade, Racionalidade e Educação: A reconstrução da teoria crítica por Habermas. In: ZUIN, Antônio Álvaro Soares; PUCCI, Bruno; RAMOS-DE-OLIVEIRA, Newton (orgs). A Educação Danificada: contribuições à teoria crítica da Educação. 2 ed. Petrópolis, RJ: Vozes; São Carlos, SP: EdUFSCAR, 1998. p. 243-263.

NOBRE, Marcos (Org.. Curso Livre de Teoria Crítica. 3 ed. Campinas: Papirus Editora, 2008.

PAGNI, P. A. Subjetividade, corpo e educação na obra de Herbert Marcuse. Perspectiva. Florianópolis, v. 21, n. 01, p. 79-119, jan./jun.2003

PRESTES, Nadja Hermann. O Polêmico debate da Educação na contemporaneidade: a contribuição Habermasiana. In: ZUIN, Antônio Álvaro Soares; PUCCI, Bruno; RAMOS-DE-OLIVEIRA, Newton (orgs). A Educação Danificada: contribuições à teoria crítica da Educação. 2 ed. Petrópolis, RJ: Vozes; São Carlos, SP: EdUFSCAR, 1998. p. 217-263.

PUCCI. Bruno. (org.) Teoria crítica e educação: a questão da formação cultural na Escola de Frankfurt. Petrópolis, RJ: Vozes; São Carlos, São Paulo: EdUFSCAR, 1994.

REPA, Luiz. Jürgen Habermas e o modelo reconstrutivo de teoria crítica. In: NOBRE, Marcos (org). Curso livre de Teoria Crítica. 3 ed. Campinas, SP: Papirus, 2008. p. 161-182. 